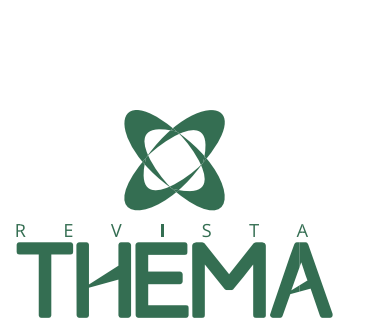

\title{
Investigação na educação em ciências: concepções e aspectos históricos
}

\author{
Research in education in sciences; conceptions and historical aspects \\ Charles Guidotti ${ }^{1}$; Valmir Heckler ${ }^{2}$
}

\section{RESUMO}

Nesse artigo, de cunho teórico, objetivamos compreender aspectos históricos do termo investigação, na Educação em Ciências. Para isso, buscamos na literatura tanto nacional quanto internacional, interlocutores teóricos associados às distintas concepções assumidas ao longo da história ao termo investigação no contexto escolar. Significamos neste contexto: os primeiros sentidos do termo investigação em Ciências nos séculos XIX e XX; a investigação em documentos oficiais: cenário norte americano e brasileiro. Além disso, buscamos ampliar compreensões acerca de como a investigação perpassa o processo formativo de professores de Ciências no Brasil.

Palavras-chave: Investigação; Educação em Ciências; Formação de Professores.

\begin{abstract}
This article, in its theoretical nature, aims to understand historical aspects about the term investigation, in Science Education. For such, theoretical interlocutors, associated with different conceptions assumed throughout history to the term investigation in school context, were researched at both nacional and international literature. In this context, we mean: the first senses of the term investigation in Sciences in the 19th and 20th centuries; the investigation in oficial documents: North American and Brazilian scenery. In addition, we objected to expand understandings about how the investigation pass through science teacher training in Brazil.
\end{abstract}

Keywords: Research; Education in Sciences; Teacher training.

1;2 FURG - Universidade Federal do Rio Grande - Rio Grande/RS - Brasil. 


\section{INTRODUÇÃO}

A investigação em sala de aula, em diferentes níveis de formação, é apontada por vários teóricos como uma forma de ultrapassar modelos de ensinar, pautados em processos de apresentação de informações (Deboer, 2006, Barrow 2006, Trópia, 2011, Grandy e Duschl, 2007, Demo, 2009, Moraes, et al., 2012, Carvalho, 2013, Sasseron e Duschl, 2016 Wells, 2016). Compreendemos que a investigação desde a escola possibilita transformações nas formas de ensinar e aprender Ciências, um processo que desafia perpassar os movimentos formativos de professores na área de Educação em Ciências.

Sob esse entendimento, buscamos nesse estudo com interlocuções teóricas, significar aspectos históricos que constituem o termo investigação, na Educação em Ciências. Realizamos interlocuções teóricas associadas às concepções de investigação, registradas a partir dos séculos XIX, XX e em documentos oficiais publicados nos Estados Unidos da América e no Brasil a partir dos anos 90 . Além disso, comunicamos as compreensões sobre como a construção histórica em torno da investigação na educação científica perpassa o processo formativo de professores de Ciências no Brasil. Esse estudo, constitui parte da pesquisa de tese de doutorado que tem como objetivo compreender as concepções de investigação desde a escola na formação de professores de Ciências.

\section{OS PRIMEIROS SIGNIFICADOS DO TEMA INVESTIGAÇÃO EM CIÊNCIAS: SÉCULOS XIX E XX}

Com base no argumento que o sistema educacional, tanto nacional quanto internacional, é fortemente influenciado pelas necessidades econômicas, culturais e sociais, apresentamos nessa seção aspectos históricos da investigação em sala de aula. Contamos essa história a partir do século XIX, pois é quando as disciplinas de Ciências passam a fazer parte do currículo escolar em vários países (GOODSON, 2013). Desde então, estudiosos da educação e do Ensino de Ciências começam a problematizar aspectos da investigação científica nas aulas de Ciências.

Registramos que as primeiras tentativas de inserir a disciplina de ciência nos currículos escolares aconteceram na Inglaterra em 1825. De acordo com Goodson (2013), a ciência escolar do referido período denominado de "ciência das coisas comuns" tinha como base as experiências dos alunos sobre a natureza, ambiente familiar, vida e ocupação do dia-dia. Limitada aos currículos de escolas da classe operária, a disciplina de ciência, dessa época, era rejeitada por grupos que não estavam interessados em que os conhecimentos desse campo do saber fossem compreendidos por todas as pessoas. Com a justificativa de que as pessoas desprovidas de condições sociais não poderiam ter capacidades intelectuais superiores àquelas que estão socialmente acima delas, por essa razão a disciplina de Ciências acabou sendo removida dos currículos escolares em 1860.

Até a primeira metade do século XIX, a matemática e a gramática foram as disciplinas que predominaram nas escolas. Apenas quando estudiosos Europeus e Americanos começaram a promover a Ciências como uma disciplina com valores diferentes das já existentes, é que por volta de 1880, ela voltou a fazer parte do currículo (DEBOER, 2006). As justificativas utilizadas para explicar a inserção da Ciência novamente nas escolas estavam fundamentadas na ideia de que os conhecimentos produzidos por ela dependiam de observações empíricas, as quais levavam a princípios gerais. Diferentemente da matemática e da gramática, disciplinas que seguem regras claras e inferências lógicas, a Ciência oferecia prática de lógica indutiva. Nessa perspectiva, os estudantes 
tinham que aprender a observar o mundo natural e formular conclusões a partir das suas observações (DEBOER, 2006). Desse modo, a Ciência retornava aos currículos escolares, se apresentando de uma forma diferente da ciência das coisas comuns.

Observamos que o médico, biólogo e presidente da Royal Society ${ }^{3}$ Thomas Huxley (1825 - 1895), foi um importante defensor da inserção da Ciência nos currículos escolares. Entusiasta das ideias de Darwin, o britânico Huxley defendia que a formação científica oportunizava aos sujeitos compreender a natureza, a partir do contato direto com os fatos reais. Assim, as práticas investigativas envolvendo o uso de laboratório passaram a ser vistas como forma correta de ciência, enquanto construção humana (DEBOER, 2006; BAPTISTA, 2010; GOODSON, 2013).

Com base na revisão das perspectivas históricas do ensino por investigação realizada por Deboer (2006), apresentamos no quadro 1, uma síntese de características, vantagens e desvantagens apontadas para três abordagens investigativas surgidas no século XIX.

Quadro 1: Síntese das abordagens investigativas do Século XIX

\begin{tabular}{|c|l|l|l|}
\hline Abordagem & \multicolumn{1}{|c|}{ Características } & \multicolumn{1}{|c|}{ Vantagem } & \multicolumn{1}{c|}{ Desvantagem } \\
\hline $\begin{array}{c}\text { Heurística (ou por } \\
\text { descoberta) }\end{array}$ & $\begin{array}{l}\text { Os estudantes tinham } \\
\text { total autonomia para } \\
\text { explorar o mundo, sem } \\
\text { quaisquer orientações de } \\
\text { material ou do professor. }\end{array}$ & $\begin{array}{l}\text { O método colocava o } \\
\text { aluno no papel de } \\
\text { descobridor. }\end{array}$ & $\begin{array}{l}\text { O método exigia muito tempo e } \\
\text { preparo dos estudantes para não } \\
\text { tirar conclusões superficiais de suas } \\
\text { investigações. }\end{array}$ \\
\hline Verificação & $\begin{array}{l}\text { Os estudantes eram } \\
\text { conduzidos a } \\
\text { confirmarem princípios } \\
\text { ou fatos científicos em } \\
\text { laboratório. }\end{array}$ & $\begin{array}{l}\text { A abordagem fortalecia } \\
\text { a compreensão dos } \\
\text { estudantes acerca dos } \\
\text { conceitos de ciência. }\end{array}$ & $\begin{array}{l}\text { O método levava os estudantes a } \\
\text { desenvolverem atitudes não } \\
\text { científicas, pois eram induzidos a } \\
\text { procurarem respostas corretas ou } \\
\text { considerar apenas as evidências em } \\
\text { que o resultado fosse o esperado. }\end{array}$ \\
\hline $\begin{array}{l}\text { Investigação } \\
\text { Orientada } \\
\text { (Inquiry }\end{array}$ & $\begin{array}{l}\text { Os estudantes não } \\
\text { tinham que descobrir } \\
\text { algo mas teriam que } \\
\text { procurar soluções para } \\
\text { questões que não sabiam } \\
\text { responder. }\end{array}$ & $\begin{array}{l}\text { Nessa abordagem os } \\
\text { estudantes agiam } \\
\text { como verdadeiros } \\
\text { investigadores, não } \\
\text { apenas simplesmente } \\
\text { confirmando algo que } \\
\text { já sabiam. }\end{array}$ & $\begin{array}{l}\text { Os estudantes seguiam } \\
\text { rigorosamente o método cientifico. } \\
\text { Estudar ciência exigia vocação e } \\
\text { preparo. }\end{array}$ \\
\hline
\end{tabular}

Fonte: Adaptado de Deboer (2006)

A contar do século XX, a educação cientifica deixa de ser uma maneira de disciplinar a mente através do raciocínio indutivo e passa a se voltar a valores sociais das Ciências (DEBOER, 2006; BARROW, 2006; MACÊDO, 2015). Desse modo, de acordo com os referidos autores, a escola deveria considerar a necessidade de formar cidadãos pertencentes a uma sociedade democrática, que tenham postura crítica, reflexiva e atuante em acontecimentos de experiências diárias.

Nesse cenário as ideias do filosofo, pedagogo e crítico dos modelos de ensino predominantes na época John Dewey (1859 - 1952), surgem como possibilidade de transformação da sociedade. Para Dewey (1976) a escola deveria levar em consideração os interesses dos estudantes e os problemas correntes

\footnotetext{
${ }^{3} \mathrm{~A}$ Real Sociedade de Londres para o Melhoramento do Conhecimento Natural é uma instituição destinada à promoção do conhecimento científico. Foi fundada em 28 de novembro de 1660. A Royal Irish Academy, fundada em 1782, é afiliada a ela.

${ }^{4} \mathrm{~A}$ partir desse momento no texto assumimos que a investigação é uma tradução do termo inquiry.
} 
da sociedade, pautado na conviç̧ão de que democracia e ciência contribuem com o progresso da sociedade.

Nesta perspectiva, Dewey (1976) aponta que a escola, em especial o Ensino de Ciências, deveria promover aprendizagens de métodos utilizados pela própria ciência. A ideia de proporcionar aos estudantes "experiências" de situações problemáticas é o ponto central da pedagogia proposta pelo filosofo norte americano. De acordo com Dewey (1976), o desenvolvimento da experiência acontece através da interação entre quem aprende e o que é aprendido, modificando assim dois elementos que nela entram; situação e agente. Com isso, o termo "experiência" na pedagogia de Dewey não está associado a aulas práticas, mas sim às atividades humanas. Nesse sentido, no modelo pedagógico sugerido por Dewey (1976), os estudantes atuariam ativamente na solução de problemas sociais, que deveriam estar de acordo com as suas experiências e o seu desenvolvimento intelectual e cognitivo. Para isso o professor, como sujeito mais experiente, desempenhava o papel de facilitador e orientador das aprendizagens.

Porém, com o lançamento do satélite soviético Sputnik, o primeiro satélite artificial a orbitar em torno da Terra em 1957, fez com que a comunidade americana questionasse a educação científica do país. Barrow (2006) afirma que cientistas, professores de Ciências e lideres indústrias passaram a defender que o Ensino de Ciências, nos Estados Unidos da América, tinha perdido o seu rigor acadêmico, pois estava demasiadamente centrado nos estudantes e em problemas de relevância social. Com a necessidade de retomar o rigor científico do Ensino de Ciências e de fazer frente aos avanços científicos e tecnológicos da União Soviética, americanos e aliados, iniciaram uma reforma educacional, que se estendeu durante as décadas de 1950, 1960 e 1970.

A partir desse momento, as Ciências tinham se tornando questão de segurança nacional e de desenvolvimento econômico (DEBOER, 2006). Com isso, a reforma educacional da época teve como objetivo central tornar os estudantes verdadeiros cientistas. Desse modo, assim como no final do século XIX, a ênfase do Ensino de Ciências estava novamente voltada aos processos científicos e no desenvolvimento de habilidades individuais, tais como: observar, classificar, inferir e controlar variáveis (BARROW, 2006).

Nesse sentido, com objetivo de desenvolver um currículo de Ciências que alinhasse ensino e pesquisa, com atenção na formação de novos cientistas, foram criados nos Estados Unidos da América a National Science Foundation (NSF) e o National Research Council (NRC). Essas e outras organizações de profissionais de Ciências e Matemática patrocinaram eventos que tinham como objetivo revisar o currículo escolar dessas disciplinas.

No quadro 2, apresentamos projetos que surgiram no final da década de 1950 e durante a década de 1960, incentivados pelas reformas curriculares.

Quadro 2: Projetos que surgiram ao final da década de 1950 e durante a década de 1960

\begin{tabular}{|c|c|}
\hline País & Projeto \\
\hline Estados Unidos da América & Physical Science Study Committee (PSSC) \\
\hline Estados Unidos da América & Biological Sciences Curriculum Study (BSCS) \\
\hline Estados Unidos da América & $\begin{array}{c}\text { Commonwealth Higher Education } \\
\text { Management Service (CHEMS) }\end{array}$ \\
\hline Estados Unidos da América & Science - a Process Approach (SAPA) \\
\hline
\end{tabular}




\begin{tabular}{|c|c|}
\hline Estados Unidos da América & Elementary Science Study (ESS) \\
\hline Estados Unidos da América & $\begin{array}{c}\text { Conceptually Oriented Program in Elementary } \\
\text { Science (COPES) }\end{array}$ \\
\hline Reino Unido & Fundação Nuffield \\
\hline Reino Unido & Cursos do School Council \\
\hline Reino Unido & Projeto Science \\
\hline
\end{tabular}

Esses projetos, principalmente aqueles produzidos nos Estados Unidos da América, influenciaram significativamente as primeiras reformas educacionais ocorridas desde a década de 1950 no Brasil. Os projetos, citados no quadro 2, estavam pautados na ideia de que a ciência deveria ser ensinada como era praticada pelos próprios cientistas (YAGER, 1981; DEBOER, 2006).

Nessa perspectiva, a investigação era assumida pela comunidade científica como modelo correto de ensinar Ciências a partir da década de 1960. De acordo com Deboer (2006), nessa época surgiram diversas denominações para o uso da investigação em sala de aula, tais como: aprendizagem por descoberta, resolução de problemas, ensino indutivo e aprendizagem por projetos. Conforme o referido autor, o modelo de investigação para ensinar Ciências, apoiado pelos projetos desenvolvidos nesse período se diferenciavam de outros modelos propostos anteriormente. Os projetos propostos nesse período exigiam dos estudantes o mesmo rigor científico desenvolvido pelos próprios cientistas ao gerarem novos conhecimentos. Joseph Schwab (1909 - 1988), professor de Ciências na Universidade de Chicago, foi um importante pensador na disseminação dessas ideias durante as décadas de 1950 e 1960.

Porém, a exigência, do rigor científico nas investigações a serem realizadas pelos estudantes, acabou deixando menos acessível à educação científica ao público em geral.

A partir da década de 1970, com o agravamento da crise ambiental e recebendo fortes críticas pelo enfoque, dado na formação de cientistas, o Ensino de Ciências volta a focar em questões sociais. Com isso, a educação científica passa objetivar a formação de cidadãos esclarecidos e com habilidades para interagir com o mundo científico. Segundo Deboer (2006), a ideia de preparar os estudantes para terem compreensões amplas e funcionais da ciência vieram a ser denominados de alfabetização científica. Dessa maneira, os conhecimentos científicos e os processos da própria ciência eram usados pelos estudantes para responder problemas encontrados na vida cotidiana, de ordem social e cultural. Na perspectiva neo-progressita, movimentos como da educação ambiental e ciência, tecnologia e sociedade (CTS) emergiram nesse período.

Neste cenário, a investigação no Ensino de Ciências tinha como objetivo orientar os estudantes na resolução de problemas práticos enfrentados pela sociedade, tais como: aquecimento global, poluição do ar e da água, eliminação de resíduos entre outros. Nesse sentido, a educação científica desse período, que se estendeu pela década de 1980, significando aos estudantes que tinham que desenvolver conhecimentos, os quais permitissem analisar e resolver questões sociais através da coleta de dados, interpretação e comunicação.

Em síntese, na tabela 1, apresentamos as principais ideias emergentes nessa seção, acerca da investigação no Ensino de Ciências do século XX. 
Tabela 1: Síntese da educação científica ao longo do século XX.

\begin{tabular}{|c|c|c|c|}
\hline & 1900 & 1957 & $1970[\ldots]$ \\
\hline $\begin{array}{l}\text { Motivação da } \\
\text { Educação } \\
\text { Científica }\end{array}$ & $\begin{array}{c}\text { Crise social (crescimento } \\
\text { urbano) }\end{array}$ & Corrida espacial & Crise ambiental \\
\hline $\begin{array}{l}\text { Foco da } \\
\text { Educação } \\
\text { Científica }\end{array}$ & $\begin{array}{l}\text { Propor respostas aos } \\
\text { problemas sociais }\end{array}$ & $\begin{array}{l}\text { Formação de } \\
\text { futuros cientistas }\end{array}$ & $\begin{array}{l}\text { Orientar os estudantes na } \\
\text { resolução de problemas } \\
\text { práticos enfrentados pela } \\
\text { sociedade }\end{array}$ \\
\hline \multirow[t]{2}{*}{$\begin{array}{l}\text { A investigação } \\
\text { em sala de aula }\end{array}$} & $\begin{array}{c}\text { Valorização da interação entre } \\
\text { estudante e objeto (estudante } \\
\text { e problema social) }\end{array}$ & $\begin{array}{l}\text { Desenvolvimento } \\
\text { de habilidades } \\
\text { individuais }\end{array}$ & \\
\hline & $\begin{array}{l}\text { Foco no estudante e em } \\
\text { problemas sociais. }\end{array}$ & $\begin{array}{c}\text { Ações } \\
\text { disciplinares }\end{array}$ & $\begin{array}{l}\text { Preparar os estudantes para } \\
\text { terem compressões amplas } \\
\text { e funcionais da ciência. }\end{array}$ \\
\hline $\begin{array}{l}\text { Termos } \\
\text { emergentes }\end{array}$ & $\begin{array}{c}\text { Inquiry } \\
\text { (Investigação) }\end{array}$ & $\begin{array}{l}\text { Aprendizagem } \\
\text { como descoberta, } \\
\text { resolução de } \\
\text { problemas, } \\
\text { ensino indutivo e } \\
\text { aprendizagem por } \\
\text { projetos. }\end{array}$ & $\begin{array}{l}\text { Alfabetização científica e } \\
\text { movimento ciência, } \\
\text { tecnologia e sociedade } \\
\text { (CTS) }\end{array}$ \\
\hline \multirow{2}{*}{$\begin{array}{l}\text { Principais } \\
\text { pensadores do } \\
\text { período }\end{array}$} & \multicolumn{3}{|c|}{ John Dewey (1859 - 1952) } \\
\hline & \multicolumn{3}{|c|}{ Joseph Schwab (1909 - 1988) } \\
\hline \multicolumn{4}{|c|}{ Valorização do método científico } \\
\hline
\end{tabular}

Na tabela 1, observamos diferentes concepções de investigação desenvolvida ao longo do século XX. Na primeira metade do século, a investigação em sala de aula tinha como foco os estudantes fornecerem soluções aos problemas sociais gerados pela crise urbana dos anos 90. Por volta de 1950, motivado pela corrida espacial, a educação científica passa a objetivar a formação de futuros cientistas, com isso, a investigação esteve centrada no desenvolvimento de habilidades individuais dos estudantes e fortemente pautada nos métodos rígidos de produção do conhecimento. Por fim, em meados de 1970 com o agravamento da crise ambiental a educação científica volta a focar na preparação dos estudantes para a resolução de problemas práticos enfrentados pela sociedade.

Portanto, ao longo do século XX, a educação cientifica como a concepção de investigação em sala de aula sofreram diversas modificações em função das necessidades políticas, econômica e sociais. Na seção seguinte, procuramos compreender a definição de investigação no século XXI, segundo documentos oficiais, publicados nos Estados Unidos da América e no Brasil.

\section{A INVESTIGAÇÃO EM DOCUMENTOS OFICIAIS: CENÁRIO NORTE AMERICANO E BRASILEIRO}

A contar da década de 1950, grande parte dos projetos curriculares, apoiados pela National Science Foundation (NSF) dos Estados Unidos da América, indicavam o uso da investigação científica em sala de aula, como sinônimo de uma educação científica de qualidade (ANDERSON, 2002). No entanto, os trabalhos realizados por Anderson (2002), Flick e Lederman (2006) e Abd-El-Khalick et al. (2015), apontam não existir um consenso acerca da definição do termo investigação (inquiry) nos projetos 
desenvolvidos até a década de 80 . Na tabela 2, com base nos referidos autores, apresentamos três distintas perspectivas para o referido termo:

Tabela 2: Concepções de investigação presentes nos projetos americanos

\begin{tabular}{c|l}
\hline $\begin{array}{c}\text { Investigação Científica } \\
\text { (Scientific Inquiry) }\end{array}$ & $\begin{array}{l}\text { Refere-se às diversas formas, pelas quais os cientistas propõem } \\
\text { explicações baseados em evidencias. Esta definição de } \\
\text { investigação reflete uma compreensão de como a ciência é } \\
\text { conduzida e é independente dos processos educacionais. }\end{array}$ \\
\hline $\begin{array}{c}\text { Aprendizagem por Investigação } \\
\text { (Inquiry learning) }\end{array}$ & $\begin{array}{l}\text { Define-se como um processo ativo de aprendizagem, na qual os } \\
\text { estudantes constroem conhecimentos de forma semelhante aos } \\
\text { cientistas. Desse modo, aprendizagem baseada na investigação } \\
\text { deve refletir a natureza da investigação científica. Os estudantes } \\
\text { aprendem a fazer investigação no contexto dos conteúdos } \\
\text { científicos desenvolvendo compreensões epistemológicas. }\end{array}$ \\
\hline $\begin{array}{l}\text { Ensino por Investigação } \\
\text { (Inquiry Teaching) }\end{array}$ & $\begin{array}{l}\text { aprendizagem de conceitos científicos. A investigação como um } \\
\text { meio destinado a ajudar os estudantes a compreenderem os } \\
\text { conteúdos científicos. }\end{array}$ \\
\hline
\end{tabular}

Fonte: Adaptado de Anderson (2002) e Abd-El-Khalick et al. (2015)

Com base na tabela 2, significamos a dupla natureza do termo investigação, que dividiu opiniões até meados da década de 80 . O primeiro sentido do termo refere-se a aprendizagem por investigação (Inquiry learning). Nesse sentido, a aprendizagem está relacionada com a investigação científica, assumindo assim a ideia de que os estudantes aprendem Ciências fazendo Ciências, de forma semelhante aos cientistas. Para Macêdo (2015), essa forma de compreender a investigação está associada a uma transposição didática equivocada, que considera a pesquisa fundamental no contexto de ensino dos saberes científico. Ele d

O segundo sentido atribuído ao termo está relacionado ao ensino por investigação (inquiry teaching). Aqui, a investigação é assumida como uma técnica de ensino, com objetivo de desenvolver habilidades nos estudantes para compreenderem os saberes científicos. Colburn (2006) define o referido termo como uma técnica de ensino em que os estudantes exploram fenômenos naturais, usando seus conhecimentos e experiências de fundo, fazendo perguntas, resolvendo problemas e criando respostas.

No entanto ao final dos anos 80, ambas as concepções de investigação, foram unificadas sob o título de alfabetização científica (DEBOER, 2006). Em uma primeira tentativa de chegar a um consenso acerca do que os estudantes precisariam saber para ser considerado alfabetizado cientificamente, 0 projeto intitulado Science For All Americans, publicado em 1989, apresentou importantes contribuições para o campo do Ensino de Ciências. O projeto sugeria que os conteúdos fossem selecionados seguindo cinco critérios:

(I) O conteúdo pode aumentar em longo prazo as perspectivas de emprego e a capacidade de tomar decisões pessoais?

(II) O conteúdo ajuda o indivíduo a "participar de forma inteligente da tomada de decisões políticas envolvendo ciência e tecnologia"?

(III) O conteúdo apresenta aspectos relacionados à ciência, matemática e tecnologia que são tão importantes na história humana ou são tão universais dentro da nossa cultura que uma educação geral estaria incompleta sem eles?

(IV) O conteúdo ajuda as pessoas a refletirem sobre as questões perenes da existência humana?

(V) O conteúdo enriquece a vida das crianças, independentemente do que eles possam ser a mais tarde na vida? (p. 19-20). 
O projeto recomendava que as investigações em sala de aula devessem ser coerentes com a natureza da investigação científica. Para isso, os estudantes deveriam aprender determinados procedimentos científicos, tais como: observar, registrar, manipular, descrever, perguntar e buscar respostas. Desse modo, atribuindo a investigação em sala de aula a instrumentalização dos estudantes para a vida, para que fossem capazes de lidar sensatamente com problemas que envolvem evidências, incertezas, considerações e a argumentação (DEBOER, 2006).

Em 1996 a National Research Council (NRC) publicou o documento intitulado National Science Education Standarts (NSES), que reconhecia as importantes contribuições da investigação científica para alfabetizar cientificamente os estudantes. De acordo com NSES, a educação científica deveria preparar os estudantes para serem capazes de:

1. Experimentar a riqueza e a excitação de conhecer e compreender o mundo natural; 2. Usar apropriadamente processos e princípios científicos na tomada de decisões pessoais;

3. Engajar-se de maneira inteligente em discursos públicos e debates sobre assuntos de interesse científico e tecnológico;

4. Aumentar sua produtividade econômica através do uso do conhecimento, compreensão e habilidades da alfabetização científica pessoal em suas carreiras (p.13).

No entanto, o termo investigação é ambiguamente definido:

A investigação científica refere-se aos diversos caminhos pelos quais os cientistas estudam o mundo natural e propõem explicações baseadas em evidências derivadas de seus trabalhos. A investigação também se refere às atividades dos estudantes nas quais eles desenvolvem o conhecimento e compreensão das ideias científicas, bem como a compreensão de como os cientistas estudam o mundo natural (p. 23).

Outros documentos norte-americanos publicados posteriormente destacam explicitamente a importância de levar a investigação para as aulas de Ciências. Nesse sentido, destacamos o volume complementar do NSES, publicado em 2000 e intitulado Inquiry and the National Science Education Standards: A Guide for Teaching and Learning. Além de inúmeras orientações para que os professores utilizem a investigação cientifica como princípio pedagógico, o documento destaca como características essenciais da investigação em sala de aula os seguintes pontos:

-Engajar os estudantes com perguntas de orientação cientifica;

-Que os estudantes deem prioridade às evidencias ao responder questões;

-Os estudantes formulem explicações a partir de provas para abordar questões cientificamente orientadas;

-Os estudantes avaliem suas explicações à luz de explicações alternativas, em particular aquelas que refletem o conhecimento científico;

-Os estudantes comuniquem e justifiquem as suas explicações propostas (p.25).

Apesar desses documentos apresentarem ampla demarcação para o termo investigação (Macêdo, 2015), compreendemos que essa seja uma das características da Educação Científica dos Estados Unidos da América. Significamos, a partir de Grandy e Duschl (2005), que essa característica, é resultado de intensas discursões acerca do papel da investigação em Ciências, que se estendem por mais de 50 anos. 
Desse modo, a partir dos referidos autores e documentos citados, observamos não haver um consenso na literatura americana em torno da caracterização da investigação em sala de aula.

No Brasil, os documentos oficiais sempre destacam a importância das abordagens investigativas no Ensino de Ciências. Com objetivo de colocar em prática todos os preceitos da Lei de Diretrizes e Bases da Educação de 1996, a contar de 1997, começaram a ser publicados os Parâmetros Curriculares Nacionais (PCNs). Esses documentos servem de referência para os ensinos fundamental e médio de todo o país e tem por finalidade auxiliar os professores nas práticas diárias de sala de aula.

Nesses documentos o termo investigação é mencionado em diversos momentos, com objetivo de propor um modelo de Ensino de Ciências. Nesse sentido, o termo investigação aparece associado à tríade do aprender Ciências, aprender a fazer Ciências e a aprender sobre Ciências.

O aprender Ciências significa oportunizar aos estudantes o acesso a ideias, modelos e teorias construídas ao longo dos tempos, conforme exemplificado na área de Física.

A Física deve apresentar-se, portanto, como um conjunto de competências específicas que permitam perceber e lidar com os fenômenos naturais e tecnológicos, presentes tanto no cotidiano mais imediato quanto na compreensão do universo distante, a partir de princípios, leis e modelos por ela construídos. Isso implica, também, na introdução à linguagem própria da Física, que faz uso de conceitos e terminologia bem definidos, além de suas formas de expressão, que envolvem, muitas vezes, tabelas, gráficos ou relações matemáticas. Ao mesmo tempo, a Física deve vir a ser reconhecida como um processo cuja construção ocorreu ao longo da história da humanidade, impregnado de contribuições culturais, econômicas e sociais, que vem resultando no desenvolvimento de diferentes tecnologias e, por sua vez, por elas impulsionado (Brasil, 2002, p.2).

Enquanto que aprender a fazer Ciências, refere-se ao inserir os estudantes na cultura da produção do conhecimento científico. De acordo com Paula (2004), é o equivalente ao desenvolver habilidades associadas à produção de conhecimento de proposições e fatos atribuídos às Ciências.

[...] Ainda na elaboração das atividades, deve-se considerar também o desenvolvimento de habilidades cognitivas, tais como: controle de variáveis, tradução da informação de uma forma de comunicação para outra, como gráficos, tabelas, equações químicas, a elaboração de estratégias para a resolução de problemas, tomadas de decisão baseadas em análises de dados e valores, como integridade na comunicação dos dados, respeito às ideias dos colegas e às suas próprias e colaboração no trabalho coletivo (Brasil, 2000, p.37).

Em relação a aprender sobre Ciências, seguindo as ideias de Paula (2004), implica levar os estudantes a compreensão, tanto dos métodos de investigação, quanto das dinâmicas sociais que caracterizam as Ciências como empreendimento cultural e social.

Não foi sem repúdio e espanto que a humanidade assistiu à explosão da bomba atômica no Japão e, ainda que sob muitos protestos, à continuidade na produção de armamento nuclear e de outras armas químicas e biológicas, de imenso potencial destrutivo. São fatos que mostram claramente a associação entre desenvolvimento científico e tecnológico e interesses políticos e econômicos. A Ciência que, acima de qualquer julgamento, domina a natureza e descobre suas leis, passa a ser percebida, então, em sua dimensão humana, com tudo que isso pode significar: trabalho, 
disciplina, erro, esforço, emoção e posicionamentos éticos. É importante, portanto, que se supere a postura que apresenta o Ensino de Ciências Naturais como sinônimo da mera descrição de suas teorias e experiências, sem refletir sobre seus aspectos éticos e culturais (Brasil, 1998, p.22, grifo nosso).

Desse modo, registramos que esses documentos assumem a investigação em sala de aula como um meio que oportuniza os estudantes aprender Ciências, aprender sobre Ciências e aprender a fazer Ciências.

A aprendizagem de concepções científicas atualizadas do mundo físico e natural e o desenvolvimento de estratégias de trabalho centradas na solução de problemas é finalidade da área, de forma a aproximar o educando do trabalho de investigação científica e tecnológica, como atividades institucionalizadas de produção de conhecimentos, bens e serviços (Brasil, 2000, p.20).

Ainda em relação aos PCNs, chamamos a atenção para o fato dos documentos unirem os termos investigação e compreensão para o desenvolvimento das mesmas competências e habilidades gerais (Brasil, 2002, p.29). No quadro 3, retirado de Brasil (2002), os documentos indicam um conjunto de competências que o processo de investigação e compreensão oportunizam aos estudantes.

Quadro 3: Competência: Investigação e Compreensão

INVESTIGAÇÃo E COMPREENSÃo
$\begin{gathered}\text { Estratégias para enfrentamento de situações-problema } \\ \text { Identificar em dada situação-problema as informações ou variáveis relevantes e possíveis estratégias } \\ \text { para resolvê-la. }\end{gathered}$
$\begin{gathered}\text { Interações, relações e funções; invariantes e transformações } \\ \text { Identificar fenômenos naturais ou grandezas em dado domínio do conhecimento científico, estabelecer } \\ \text { relações; identificar regularidades, invariantes e transformações. }\end{gathered}$
Medidas, quantificações, grandezas e escalas
Selecionar e utilizar instrumentos de medição e de cálculo, representar dados e utilizar escalas, fazer
estimativas, elaborar hipóteses e interpretar resultados.
Modelos explicativos e representativos
Reconhecer, utilizar, interpretar e propor modelos explicativos para fenômenos ou sistemas naturais ou
tecnológicos.

Fonte: Quadro reproduzido de Brasil (2002, p. 30)

Seguindo as mesmas ideias dos PCNs, a Base Comum Curricular (BCC) de 2016, a investigação científica também aparece como uma das competências a serem desenvolvidas pelas disciplinas que compõem a área de Ciências da Natureza.

Compreender conceitos fundamentais e estruturas explicativas das Ciências da Natureza, bem como dominar processos, práticas e procedimentos da investigação científica, de modo a sentir segurança no debate de questões científicas, tecnológicas e socioambientais e do mundo do trabalho (Brasil, 2016, p.276).

Dessa forma, é possível observar que as ideias apresentadas nos documentos oficiais nacionais fundamentam um trabalho em sala de aula, pautado em práticas investigativas. Entretanto, diferentemente dos documentos norte-americanos, que apresentam inúmeros exemplos de como 
deve acontecer a investigação em sala de aula, os documentos nacionais apenas mencionam o termo investigação como meio para o desenvolvimento de habilidades e competências.

Enquanto que nos Estados Unidos da América há mais de 50 anos se debate aspectos da investigação nas aulas de Ciências, no Brasil apenas a partir da publicação dos PCNs em 1997, as comunicações que problematizam o tema começam a surgir (MUNFORD; LIMA, 2007; TRÓPIA, 2011; CARVALHO, 2013; WARTHA; LEMOS, 2016; ZOMPERO e LABURÚ, 2016). Entretanto, a maioria dos trabalhos nacionais têm como objetivo caracterizar a investigação como atividade de ensino e poucos deles se preocupam em olhar para os processos formativos dos professores.

A partir disso, emerge a inquietação de compreender como o termo investigação perpassa historicamente os processos formativos de professores no Brasil. Nesse sentido, na próxima seção, buscamos estabelecer relações de aspectos históricos da educação científica aos processos formativos de professores em âmbito nacional.

\section{ASPECTOS HISTÓRICOS DA EDUCAÇÃO CIENTÍFICA NO PROCESSO FORMATIVO DE PROFESSORES NO BRASIL}

Com a necessidade de alavancar o progresso científico e tecnológico, em meados do século XX, no Brasil $^{5}$ o Ensino de Ciências começou a ser reformulado, sendo fortemente influenciado pelos grandes projetos desenvolvidos na Europa e nos Estados Unidos da América (quadro 1). Nesse momento da história, período pós-segunda guerra mundial, a sociedade brasileira buscava se tornar autossuficiente, a fim de superar a dependência de matéria prima e produtos industrializados de outras nações. Para isso, o desenvolvimento científico do país era fundamental.

Os reflexos das necessidades impostas pelo processo de industrialização no país foram sentidos no sistema educacional em 1961 com a promulgação da lei 4.024 - Diretrizes e Bases da Educação (LDB) de 20 de dezembro. A lei que instituía a criação do Plano Nacional de Educação (PNE), inseriu conteúdos de Ciências no currículo escolar desde o $1^{\circ}$ ano do curso ginasial e ampliou a carga horária nas disciplinas de Física, Química e Biologia no curso colegial.

Com as discussões, motivadas pela LDB (Lei de Diretrizes e Bases) de 1961, a renovação curricular brasileira provocou a implantação de diversos projetos. Os referidos projetos receberam apoio do Instituto Brasileiro de Educação, Ciências e Cultura $(\mathrm{IBECC})^{6}$, da Fundação Brasileira para o Desenvolvimento do ensino de Ciências (FUNBEC) e de seis centros de Ciências implantados e no ano de 1965, por meio de parcerias com universidades federais, em diferentes regiões do país:

Quadro 3: centros de Ciências criados em seis capitais brasileiras no ano de 1965

\begin{tabular}{|c|c|c|}
\hline Projeto & Vinculo institucional & Cidade \\
\hline $\begin{array}{c}\text { Centro de Ensino de } \\
\text { Ciências do Nordeste } \\
\text { (CECINE) }\end{array}$ & Universidade Federal de Pernambuco & Recife- PE \\
\hline $\begin{array}{c}\text { Centro de Ciências de São } \\
\text { Paulo (CECISP) }\end{array}$ & Universidade de São Paulo & São Paulo- SP \\
\hline $\begin{array}{c}\text { Centro de Ciências do Rio } \\
\text { de Janeiro (CECIERJ) }\end{array}$ & Universidade Federal da Guanabara & Rio de Janeiro- RJ \\
\hline
\end{tabular}

\footnotetext{
${ }^{5}$ A inserção do Ensino de Ciências, ainda que de forma não obrigatória, nas escolas brasileiras aconteceu a partir de 1920.

${ }^{6}$ Criado no Rio de Janeiro em 1946 por recomendação da Organização das Nações Unidas para a Educação, a Ciência e a Cultura (UNESCO), tinha como objetivo promover projetos no campo da educação científica.
} 


\begin{tabular}{|c|c|c|}
\hline $\begin{array}{c}\text { Centro de Ciências da } \\
\text { Bahia (CECIBA) }\end{array}$ & Universidade Federal da Bahia & Salvador- BA \\
\hline $\begin{array}{c}\text { Centro de Ciências do Rio } \\
\text { Grande do Sul (CECIRS) }\end{array}$ & Universidade Federal do Rio Grande do Sul & Porto Alegre- RS \\
\hline $\begin{array}{c}\text { Centro de Ciências de } \\
\text { Minas Gerais (CECIMIG) }\end{array}$ & Universidade Federal de Minas Gerais & Belo Horizonte- MG \\
\hline
\end{tabular}

Fonte: Adaptado de Nardi (2005)

Os centros de ciências, no Brasil, tinham como foco a melhoria do ensino científico na educação formal. De acordo com Jacobucci (2006), os centros de Ciências brasileiros eram diferentes dos centros criados nos Estados Unidos, Canadá, Inglaterra, Holanda e Japão, que tinham como preocupação a função educativa e de divulgação científica desses espaços. No Brasil, os centros tinham como objetivo qualificar os professores de Ciências da Educação Básica, traduzir e implantar projetos de ensino estrangeiros, distribuir livros-texto, materiais para laboratório (NARDI, 2005) e desenvolver programas que promovessem a educação científica no país, como feiras de Ciências, edição de revistas científicas entre outras ações.

Influenciados pelos grandes projetos internacionais ${ }^{7}$ de 1960, os projetos brasileiros enfatizavam o uso do método científico para a resolução de problemas. Entretanto, os projetos estavam fundamentados numa visão, que transmitia aos estudantes uma imagem descontextualizada e socialmente neutra da ciência. Nesse cenário, segundo Borges (2010), a introdução de aulas práticas era vista como fator de melhoramento desse ensino, com o objetivo de oportunizar os estudantes a aprenderem Ciências através da descoberta.

Os projetos eram elaborados por especialistas em Ensino de Ciências, que além de serem fortemente influenciados pelos projetos internacionais, seguiam as suas próprias concepções de ciência, escola e sociedade. Portanto, as elaborações dos projetos de ensino não contavam com a participação dos professores (GOUVEIA, 1995).

Para que as ideias fomentadas nos projetos chegassem nas salas de aulas, do Brasil os centros de Ciências desenvolveram inúmeros cursos de treinamento de professores. Apesar de, segundo Gouveia (1995), a reforma educacional de 1961 fomentava a necessidade de desenvolver o espirito crítico dos estudantes através do método científico, os cursos de treinamento para professores não permitiam dúvidas sobre o novo método de ensino, uma vez que, essa forma de ensinar era compreendida pelos especialistas como a melhor. Desse modo, ficando a cargo dos professores apenas a execução dos projetos nas escolas, procurando ajustá-las a sua realidade. Gouveia (1995) resume as principais características dos cursos de treinamento, desenvolvidos pelos centros, nesse período:

1) Os cursos de Ciências eram apoiados em um projeto de ensino.

2) O professor (aluno dos cursos) não questionava sua realidade; embora identificasse seus problemas, não os situava no âmbito da política educacional vigente.

3) Dentro das limitações, o curso preocupava-se com o conteúdo, o método, a técnica, os materiais didáticos [usados no ensino] de Ciências, buscando possibilidades de aplicação na situação real de sala de aula.

4) Os cursos pretendiam que o professor se conscientizasse da necessidade de melhorar a sua ação docente na escola, a fim de tornar o Ensino de Ciências ativo e relevante.

\footnotetext{
${ }^{7}$ Exemplos de grandes projetos internacionais que foram traduzidos e aplicados em escolas brasileiras: Physical Science Study (PSSC) e Biological Science Study (BSCS).
} 
5) As possíveis soluções para problemas de sala de aula eram buscadas nos projetos estudados no curso, "adequando-os" à realidade.

6) Embora a realidade do professor fosse considerada, não era o fator mais importante, o que prevalecia eram as propostas dos projetos curriculares.

7) O ponto de partida para o curso era o projeto de ensino e o de chegada também, pois nele estavam articulados objetivos, conteúdos, métodos e materiais de laboratório. Eles orientavam o ensino. As necessidades de cada classe deveriam ser ajustadas a ele; esse era o significado de adequá-lo à realidade do aluno (p.240).

Durante a década de 1970, o Ensino de Ciências brasileiro esteve pautado nas concepções empirista de ciência (NASCIMENTO et al., 2010). Dessa forma, compreendia-se que os estudantes precisavam vivenciar o método científico para aprender Ciências. Nessa perspectiva, as abordagens investigativas deviam oportunizar os aprendizes a estabelecer problemas de pesquisa, elaborar hipóteses, planejar e realizar experimentos, analisar variáveis e aplicar os resultados obtidos a situações práticas, como cita Nascimento et al (2010):

As atividades didáticas pressupunham a resolução de problemas, através de etapas bem demarcadas, que deveriam possibilitar aos estudantes pensar e agir cientificamente. Suas finalidades educativas consistiam na valorização de sua participação ativa, no desenvolvimento de uma postura de investigação, na observação criteriosa, na descrição de fenômenos científicos e, consequentemente, na aquisição da capacidade de explicação científica do mundo (p. 228).

Procurando atender as demandas impostas pela nova LDB (Lei de Diretrizes e Bases) de 11 de agosto de 1971, embora as traduções e adaptações dos projetos internacionais continuassem, ampliou-se a produção de projetos nacionais voltados para os ensinos de primeiro e segundo grau (GOUVÊIA, 1995). No entanto, os professores continuavam não participando da elaboração dos projetos, ficando a cargo deles apenas a aplicação e avaliação dos materiais produzidos por especialistas em Ensino de Ciências.

Os centros de Ciências continuavam organizando os cursos de treinamento para professores. Os referidos cursos tinham como foco de que os professores em treinamento abandonassem os seus métodos de ensino e colocassem no lugar algo que era considerado melhor pelos especialistas (GOUVEIA, 1995, p. 244). Consequentemente, de acordo com referida autora, os cursos para professores tinham as mesmas características dos cursos de treinamento, desenvolvidos na década anterior, acrescentando três novas:

8) Os cursos procuraram introduzir temas sobre avaliação e, consequentemente, técnicas para a elaboração de instrumentos de avaliação e determinação de objetivos.

9) Há preocupação em se conhecer a realidade através de pesquisas educacionais, para subsidiar tecnicamente a elaboração de projetos de ensino.

10) Houve incentivo, nesse período, para a elaboração de propostas nacionais em contraposição à tradução de textos que predominou na década anterior (p.245).

A partir de 1970, no Brasil, ocorreu a expansão do número de vagas nos cursos de nível superior em função da demanda de estudantes egressos do segundo grau. A ampliação do ensino superior, associado às preocupações com o Ensino de Ciências e o retorno de mestres e doutores formados no exterior motivam na década de 70, a criação de diversos grupos de pesquisa e de programas de pós- 
graduação. Segundo Nardi (2005), o primeiro programa brasileiro de pós-graduação na área do Ensino de Ciências foi organizado pelo Instituto de Física da Universidade de São Paulo (IFUSP).

Ainda referente à década de 1970, registramos o início ${ }^{8}$ de eventos nacionais com foco em discussões de questões acerca do Ensino de Ciências e da formação de professores. No quadro 4, mencionamos alguns desses eventos:

Quadro 4: Eventos nacionais específicos para debater questões relacionadas ao Ensino de Ciências

\begin{tabular}{|c|c|c|}
\hline Nome do Evento & Primeira Edição & Associação Promotora \\
\hline $\begin{array}{c}\text { Simpósio Nacional de Ensino de } \\
\text { Física (SNEF) }\end{array}$ & 1970 & Sociedade Brasileira de Física (SBF) \\
\hline $\begin{array}{c}\text { Encontros e Debates sobre o Ensino } \\
\text { de Química (EDEQ) }\end{array}$ & 1980 & $\begin{array}{c}\text { Sociedade Brasileira de Química } \\
\text { (SBQ) }\end{array}$ \\
\hline $\begin{array}{c}\text { Encontro Nacional de Ensino de } \\
\text { Química (ENEQ) }\end{array}$ & 1982 & $\begin{array}{c}\text { Sociedade Brasileira de Química } \\
\text { (SBQ) }\end{array}$ \\
\hline $\begin{array}{c}\text { Encontro de Pesquisa em Ensino de } \\
\text { Física (EPF) }\end{array}$ & 1986 & $\begin{array}{c}\text { Sociedade Brasileira de Física (SBF) } \\
\text { Associação Brasileira de Ensino de } \\
\text { Biologia (SBEnBio) }\end{array}$ \\
\hline $\begin{array}{c}\text { Encontro: Perspectivas do Ensino de } \\
\text { Biologia (EPEB) }\end{array}$ & 1982 & \\
\hline
\end{tabular}

Na década de 1980, período de significativas mudanças na sociedade brasileira, a área do Ensino de Ciências transformou-se numa importante e emergente área acadêmica, graças ao apoio da Coordenação de Aperfeiçoamento de Pessoal do Ensino Superior (CAPES), para projetos de educação científica (NARDI, 2005). Desse modo, potencializando iniciativas de grupos de professores para a criação, o fortalecimento de grupos de pesquisa e a expansão de programas de pós-graduação.

Ao contrário das décadas anteriores, nesse período, as propostas para o Ensino de Ciências passaram a considerar a subjetividade e as complexas relações entre ciência, tecnologia e sociedade (CTS) da atividade científica. Por conseguinte, a educação científica deveria oportunizar aos estudantes irem além de aspectos internos da investigação científica, segundo Krasilchik (2000), como oportunizar relações destes com aspectos políticos, econômicos e culturais. Desta maneira, o Ensino de Ciências passou a articular o conteúdo científico a problemas sociais de relevância para os estudantes.

Nesse sentido, o Ensino de Ciências começou a seguir os pressupostos da didática na resolução de problemas, oportunizando aos estudantes vivenciar processos da investigação científica, com objetivo de interpretarem e agirem de forma crítica a problemas do mundo em que viviam. Consequentemente, nesse período, emergem projetos que inserem temáticas como poluição, lixo, fontes de energia, economia de recursos naturais, crescimento populacional, demandando tratamento interdisciplinar (KRASILCHIK, 2000, p. 89). Esses projetos, segundo Nascimento et al. (2010), em grande parte estavam fundamentados pelas teorias cognitivistas $^{9}$, que consideram a construção do conhecimento como produto da interação do sujeito e do mundo externo.

\footnotetext{
8 De acordo com Nardi (2005), registramos o início de associações científicas específicas, como a Sociedade Brasileira de Física (SBF), criada em 1966, Sociedade Brasileira de Química (SBQ), fundada em 1977 e a Sociedade Brasileira de Astronomia (SBA), fundada em 1974, foram responsáveis pelo início dos eventos nacionais.

${ }^{9}$ De acordo com Moreira (2011), o cognitivismo surge como uma reação ao behaviorismo clássico. Segundo o referido autor, o cognitivismo, trata-se de uma orientação psicológica que se ocupa muito mais de variáveis intervenientes do tipo cognição e intenções, dos chamados
} 
Ainda na década de 1980, de acordo com Gouveia (1995), há uma mudança no sentido atribuído ao papel desempenhado pelo professor, passando a participar ativamente das mudanças educacionais. Segundo Jacobucci (2006), a figura do educador como agente político ganhou força em detrimento da figura do professor que apenas organizava as condições de ensino e aprendizagem, amplamente divulgadas nos anos 70.

Nesse cenário, ao longo da década de 80 foram estruturados cursos de formação de professores, que consideravam os docentes como autores de propostas de mudanças. Entretanto, nesse período ainda era possível identificar cursos que seguiam as ideias de décadas anteriores. A partir de Gouveia (1995), no quadro 5, registramos em síntese as principais características dos cursos de formação de professores do referido período.

Quadro 5: Síntese das principais características dos cursos de formação de professores.

\begin{tabular}{|c|c|c|}
\hline \multicolumn{2}{|c|}{$\begin{array}{l}\text { Cursos estruturados a partir de } \\
\text { um determinado projeto de } \\
\text { ensino } \\
\text { (Modelo de curso predominante } \\
\text { na década de } 60 \text { ) }\end{array}$} & $\begin{array}{l}\text { - A preocupação era a aplicação dos projetos de ensino a } \\
\text { situações reais de sala de aula. } \\
\text { - A realidade do professor era discutida, no entanto o que } \\
\text { prevalecia eram as propostas de ensino. } \\
\text { - O ponto de partida e chegada dos cursos era o projeto de } \\
\text { ensino. } \\
\text { - Os cursos tinham como objetivo que o professor compreende-se } \\
\text { a necessidade de melhorar a sua ação docente na escola, a fim } \\
\text { de tornar o Ensino de Ciências ativo e relevante. }\end{array}$ \\
\hline \multirow[t]{2}{*}{$\begin{array}{l}\text { Cursos não } \\
\text { estruturados a } \\
\text { partir de um } \\
\text { determinado } \\
\text { projeto de } \\
\text { ensino }\end{array}$} & $\begin{array}{l}\text { Modelo A } \\
\text { (Modelo de } \\
\text { curso } \\
\text { predominante } \\
\text { na década de } \\
70 \text { ) }\end{array}$ & $\begin{array}{l}\text { - Desenvolvem temas que julgam ser importantes para o ensino } \\
\text { de } 10 \text { grau. } \\
\text { - Não se preocupam com a realidade escolar e nem com o dia-dia } \\
\text { do professor } \\
\text { - O ponto de partida e de chegada do curso era o próprio tema. } \\
\text { - Professor não pesquisava a sua realidade. } \\
\text { - Os problemas de melhoria do ensino não eram abordados. Ou } \\
\text { quando eram, ficavam circunscritos ao tema e técnicas de } \\
\text { ensino. }\end{array}$ \\
\hline & $\begin{array}{l}\text { Modelo B } \\
\text { (Modelo de } \\
\text { cursos que } \\
\text { passaram a ser } \\
\text { ofertados na } \\
\text { década de 80) }\end{array}$ & $\begin{array}{l}\text { - O ponto de partida e de chegada era a realidade escolar e a } \\
\text { prática docente. } \\
\text { - Os problemas de melhoria de ensino eram tratados no contexto } \\
\text { social e político, com objetivo de buscar melhor entendimento e } \\
\text { conscientização para os problemas educacionais e assim poder } \\
\text { escolher as suas mudanças. } \\
\text { - Colocavam a pesquisa como prática necessária para que os } \\
\text { próprios professores a realizassem e conhecessem sua } \\
\text { realidade, para então fazerem as suas propositas de ensino. } \\
\text { - Durante os cursos, os professores planejavam, aplicavam e } \\
\text { avaliavam suas propostas de ensino. } \\
\text { - A prática docente era a matéria prima dos cursos. }\end{array}$ \\
\hline
\end{tabular}

Fonte: Adaptado de Gouveia (2005, p. 250)

O movimento de globalização no início da década de 90 explicitou a necessidade da educação científica levar os estudantes a desenvolverem o pensamento crítico e reflexivo, por meio da problematização das relações existentes entre ciência, tecnologia e sociedade. Com isso, Nascimento et al. (2010) afirmam que nesse período o Ensino de Ciências passou a contestar as metodologias ativas e a incorporar o discurso da formação do cidadão crítico, consciente e participativo.

Esse movimento intensificou-se em 1996, com a aprovação da Lei de Diretrizes e Bases da Educação, no 9.394/96. A nova LDB estabeleceu, em seu artigo 1 parágrafo 2, que o "sistema educacional 
brasileiro teria como finalidade a preparação dos estudantes para o exercício da cidadania e da sua qualificação para o trabalho". Para colocar em prática todas as prescrições da nova lei, em 1997 são elaborados os Parâmetros Curriculares Nacionais (PCNs) e em 1998 o Exame Nacional do Ensino Médio (ENEM). Essas medidas institucionais colaboraram com a difusão do movimento CTS no país (VILLANI et al., 2007).

A partir dessas ações governamentais, as escolas de ensino fundamental e médio deveriam proporcionar aos estudantes, práticas de ensino que tenham como foco a formação de um cidadão autônomo e participativo. De modo a possibilitar aos estudantes não apenas a formação de habilidades cognitivas, mas também sociais (NASCIMENTO et al., 2010). Portanto, essa formação deveria ter como objetivo o desenvolvimento de competências, para que os estudantes fossem capazes de questionar a realidade, de pesquisar informações em diferentes fontes, analisa-las, seleciona-las e de utilizar recursos tecnológicos.

Para isso, a formação de professores em exercício na Educação Básica, recebeu especial atenção do Ministério da Educação e de instituições públicas, que financiaram inúmeros projetos envolvendo a formação desses professores. Segundo Nascimento et al. (2010), esses cursos objetivavam romper com uma educação descontextualizada e compartimentalizada, que valorizava o acúmulo de informações pelos estudantes. Esse movimento de mudança de paradigma, mobilizou o pensamento educacional brasileiro a focalizar na formação do professor pesquisador-reflexivo (JACOBUCCI, 2006). Nessa perspectiva, os cursos de formação de professores de Ciências passaram a estar pautados na reflexão docente das práticas de Ensino desenvolvidas na escola.

Consequentemente, no campo da pesquisa, a sala de aula torna-se um importante espaço de investigação. Seguindo essa perspectiva, as pesquisas em ensino passaram a considerar a subjetividade dos professores, assim como os conhecimentos e o saber-fazer por eles mobilizados na ação cotidiana de sala de aula (TARDIF, 2012). Desse modo, os professores deixaram de ser objetos de pesquisa, para sujeitos que possuem saberes específicos ao seu trabalho.

Ao final da década de 1990 e início do século XXI, a educação científica começou a promover problematizações em torno da responsabilidade social e ambiental de todos os sujeitos. Desse modo, questões relacionadas à formação cidadã deveriam ser o foco central da educação científica (NASCIMENTO et al., 2010. Nessa perspectiva o Ensino de Ciências defendido, na contemporaneidade, fomenta a instrumentalização dos estudantes para atuarem numa sociedade em constante transformação (DEMO, 2009).

Nesse cenário, a formação de professores é compreendida como fundamental para gerar transformações educativas e sociais (DEMO, 2009; IMBERNÓN, 2009; NASCIMENTO et al., 2010; CARVALHO; PEREZ, 2011). Desse modo, significamos que atualmente a formação continuada de professores deva estar pautada na concepção de descontruir e reconstruir práticas de ensino com fundamento da (e com a) teoria. Para isso, compreendemos que a prática da pesquisa, seguida da reflexão docente são essenciais para o desenvolvimento docente (DEMO, 2009).

\section{CONSIDERAÇÕES FINAIS}

A partir desse estudo compreendemos aspectos centrais da constituição histórica do termo investigação na Educação em Ciências. Inicialmente, significamos que as propostas de investigação no século XIX, estavam pautados no rigor da observação e do raciocínio indutivo. Nessa perspectiva, 
registramos que a investigação era uma forma de tornar aprendizagem do estudante autônoma e independente do professor. Enquanto que a partir do século XX, com base nas ideias propostas por John Dewey, a investigação em sala de aula passa a ser entendida como meio que oportuniza diversas interações, entre professor-estudante, estudante-estudante, informação-estudante-professor.

Outro aspecto evidenciado historicamente é que o termo investigação em sala de aula está presente em diversos documentos oficiais, tanto nacionais quanto internacionais, como sinônimo de um Ensino de Ciências de qualidade. Entretanto, para tal afirmação ser verdadeira, registramos que a investigação em sala de aula, seja na Educação Básica, na formação inicial e/ou permanente de professores, perpassa necessariamente, pelas ações pedagógicas e epistemológicas do professor (SASSERON, 2013).

Nesse sentido, compreendemos que a investigação em sala de aula deva estar pauta na observação, reflexão, argumentação, escrita, interação e comunicação. Uma vez que, a construção do conhecimento pode tomar uma variedade de formas, mas todas são, por natureza, essencialmente sociais e dialógicas (WELLS, 2016). Nesse sentido, aprendizagem através da investigação acontece com o envolvimento ativo e do diálogo, desde a escola, possibilita transformações nas formas de ensinar e aprender Ciências.

\section{REFERÊNCIAS}

ABD-EL-KHALICK, Fouad; LEDERMAN, Norman G.; SCHWARTZ, Renee. Inquiry, As a Curriculum Strand. Encyclopedia of Science Education, p. 510-514, 2015.

American Association for the Advancement of Science (AAAS). Science for All Americans. Washington, D.C.,1989.

ANDERSON, Ronald D. Reforming science teaching: What research says about inquiry. Journal of science teacher education, v. 13, n. 1, p. 1-12, 2002.

BAPTISTA, M. L. M. Concepções e implementação de actividades de investigação: um estudo com professores de física e química do ensino básico. Tese (doutorado), Instituto de Educação, Universidade de Lisboa, Lisboa, 2010.

BARROW, L. H. A brief history of inquiry: From Dewey to standards. Journal of Science Teacher Education, v. 17, n. 3, p. 265-278, 2006.

\section{BORGES, R.C.P. Formação de professores para o Ensino de Ciência baseado na}

investigação. Tese (Doutorado), Faculdade de Educação, Universidade de São Paulo, São Paulo, 2010.

BRASIL. Base Nacional Comum Curricular. Ministério da Educação. Brasília, Brasil, 2016.

Diretrizes e bases da Educação. Lei número 9.394 de 20/12/1996.

Diretrizes e bases da Educação. Lei número 4.024 de 20/12/1961.

. Diretrizes e bases da Educação. Lei número 5.692 de 11/8/1971.

. Ministério da Educação. PCN + Ensino Médio: Orientações educacionais

complementares aos Parâmetros Curriculares Nacionais - Ciências da Natureza e suas

Tecnologias/ Secretaria de Educação Média e Tecnológica: MEC; SEMTC, 2002. 
. Secretaria de Educação Fundamental. Parâmetros curriculares nacionais: Ciências naturais. Brasília: MEC, SEF, 1998.

. Secretaria de Educação Média e Tecnológica. Parâmetros Curriculares Nacionais para o Ensino Médio. Brasília: MEC, SEMTEC, 2000.

. Secretaria de Educação Média e Tecnológica. PCN+ Ensino Médio: orientações educacionais complementares aos Parâmetros Curriculares Nacionais. Ciências da Natureza, Matemática e suas Tecnologias. Brasília: MEC, SEMTEC, 2002.

CARVALHO, A. M. P; et al. Ensino de Ciências por investigação: condições para implementação em sala de aula. São Paulo: Cengage Learning, p. 1-20, 2013.

CARVALHO, A. M. P; GIL-PEREZ, D. Formação de professores de Ciências: tendências e inovações. 6a Ed. São Paulo: Cortez, 2011. 120 p.

COLBURN, A. What teacher educators need to know about inquiry-based instruction. Paper presented at the annual meeting of the Association for the Education of Teachers in Science, Akron, OH, 2006. Disponível em: < http://www.csulb.edu/ acolburn/AETS.htm >. Acesso em: 20 de abril de 2017.

DEBOER, G. E. Historical perspectives on inquiry teaching in schools, in: teacher education organizado por FLICK, L.B. \& LIDERMAN, N.G. Scientific inquiry and nature of science: implications for teching, learning and Springer, 2006.

DEMO, P. Educação Hoje: "Novas" Tecnologias, Pressões e oportunidades. São Paulo: Atlas, 2009. DEWEY, J. Experiência e educação. São Paulo: Companhia Editora Nacional, 1976.

FLICK, L.; LEDERMAN, NG Investigação científica e natureza da ciência. Tendências Contemporâneas e Questões na Educação em Ciência, 2006.

GOODSON, I. F. Currículo: teoria e história. Petrópolis: Vozes, 2013.

GOUVEIA, M. S. F. Ensino de Ciências e formação continuada de professores: algumas considerações históricas. Educação e Filosofia, v. 9, n. 17, p. 227-257, 1995.

GRANDY, R; DUSCHL, R. A. Reconsidering the character and role of inquiry in school science: Analysis of a conference. Science \& Education, v. 16, n. 2, p. 141-166, 2007.

IMBERNÓN, F. Formação permanente do professorado: novas tendências. São Paulo: Cortez, 2009. 120 pp.

JACOBUCCI, D. F. C. A formação continuada de professores em Centros e Museus de Ciências no Brasil. Tese (Doutorado). Faculdade de Educação, Universidade Estadual de Campinas, Campinas, 2006.

KRASILCHIK, M. Reformas e realidade: o caso do ensino das Ciências. São Paulo em perspectiva, v. 14, n. 1, p. $85-93,2000$.

MACÊDO, R. S. O Ensino de Ciências por investigação e a prática pedagógica de professores licenciados no IF-UFBA. Tese (Doutorado). Programa de Pós-Graduação em Ensino, Filosofia e História das Ciências. Universidade Federal da Bahia, Salvador, 2015. 
MORAES, R.; GALIAZZI, M. C.; RAMOS, M. G. Pesquisa em sala de aula: fundamentos e pressupostos. In: Moraes, R. e Lima, V.M.R (Orgs.). Pesquisa em Sala de Aula: tendências para a Educação em Novos Tempos. Porto Alegre: Editora EDIPUCRS, p 11-20, 2012.

MUNFORD, D; LIMA, M. E. C. Ensinar Ciências por investigação: em quê estamos de acordo?. Ensaio Pesquisa em Educação em Ciências (Belo Horizonte), v. 9, n. 1, p. 89-111, 2007.

NARDI, R. A área de Ensino de Ciências no Brasil: fatores que determinaram sua constituição e suas características segundo pesquisadores brasileiros. Tese (Livre Docência). Faculdade de Ciências, Universidade Estadual Paulista, Bauru. 2005.

NASCIMENTO, F; et al. O Ensino de Ciências no Brasil: história, formação de professores e desafios atuais. Revista HISTEDBR On-line, Campinas, n.39, p. 225-249, 2010.

PAULA, H. F. A ciência escolar como instrumento para a compreensão da atividade científica. Tese (Doutorado). Faculdade de Educação, Universidade Federal de Minas Gerais, Belo Horizonte, 2004.

SASSERON, L. H; DUSCHL, R.A. Ensino de Ciências e as Práticas Epistêmicas: O Papel do Professor e o Engajamento dos Estudantes. Investigações em Ensino de Ciências, v. 21, n. 2, p. 52, 2016.

SASSERON, Lúcia Helena. Interações discursivas e investigação em sala de aula: o papel do professor. Ensino de Ciências por investigação: condições para implementação em sala de aula. 1ed. São Paulo: Cengage Learning, v. 1, p. 41-62, 2013.

TARDIF, M. Saberes Docentes e Formação profissional. Petrópolis: Vozes, 2012. 325 p.

TRÓPIA, G. Percursos históricos de ensinar Ciências através de atividades investigativas. Ensaio Pesquisa em Educação em Ciências, v. 13, n. 1, p. 121, 2011.

UNITED STATES. National Research Council. Inquiry and the National Science Standards: A guide for teaching and learning. New York, National Academy Press, 2000.

UNITED STATES. National Research Council. National Science Education Standards. Washington, National Academy Press, 1996.

VILLANI, A; PACCA, J, L; FREITAS, D. Science teacher education in Brazil: 1950-2000. Science \& Education, v. 18, n. 1, p. 125-148, 2009.

WARTHA, E. J; LEMOS, M. M. Abordagens investigativas no Ensino de Química: limites e possibilidades. Amazônia: Revista de Educação em Ciências e Matemáticas, v. 12, n. 24, 2016.

WELLS, G. Aprendizagem Dialógica: o processo dos seres humanos de falar em direção à compreensão. In: GALIAZZI, M. C; et al. Indagações Dialógicas com Gordon Wells. Rio Grande: Editora da FURG, 2016. p. $47-87$.

YAGER, R, E. What Research Says to the Science Teacher, Volume 3. 1981.

ZOMPERO, A. F; LABURÚ, C. E. Atividades investigativas para as aulas de Ciências. Curitiba: Appris, 2016. 